\title{
As artes da ficção \\ Oliveira Vianna e a imaginação literária regionalista de Godofredo Rangel e Afonso Arinos*
}

\author{
The arts of fiction \\ Oliveira Vianna and the regionalist literary imagination \\ on the works of Godofredo Rangel and Afonso Arinos
}

\author{
LUCIANA MURARI \\ Doutora em História Social \\ Professora da Universidade de Caxias do Sul \\ Programa de Pós-graduação em Letras, Cultura e Regionalidade \\ Rua Francisco Getúlio Vargas, 1130. Bloco L. \\ Caxias do Sul (RS) 95.070-560 \\ Imurari@hotmail.com
}

RESUMO Este artigo busca estabelecer algumas das possíveis convergências entre a obra de Oliveira Vianna e a literatura regionalista produzida no Brasil entre o final do século XIX e as primeiras décadas do século XX. A afinidade programática entre os trabalhos sociológicos de Vianna e o projeto literário de valorização das comunidades interioranas brasileiras permite estabelecer pontos de contato entre os dois conjuntos de textos. Concentrando-nos nos livros publicados pelo sociólogo até a década de 1930 e adotando como referências os trabalhos ficcionais escritos pelos mineiros Afonso Arinos e Godofredo Rangel, observamos que a definição da identidade brasileira a partir da influência do mundo rural e o elogio do passado histórico como forma de estabelecimento da superioridade das elites tradicionais são temas em comum ao discurso literário e à pesquisa

Artigo recebido em 26/05/2010. Aprovado em 16/03/2011. 
de Oliveira Vianna, sobretudo em função de seu interesse pelos estudos culturais.

Palavras-chave Oliveira Vianna, literatura regionalista, identidade nacional

ABSTRACT This article intends to observe possible convergences between the sociological studies by Oliveira Vianna and regionalism in Brazilian literature from the last years of the $19^{\text {th }}$ century to the first decades of the $20^{\text {th }}$. As a start point, this literary trend and the books by Vianna have in common an interest in describing and understanding Brazilian inland communities. Focusing on his sociological works published until the 1930's and the fictional literature written by Afonso Arinos and Godofredo Rangel, both born in Minas Gerais, we realize that they share ideas like the rural origin of Brazilian mentality and the praise of history as a way to establish the superiority of traditional elites, considering the attention given by Vianna to cultural issues.

Keywords Oliveira Vianna, regionalist literature, Brazilian national identity

Evocando esse passado, para o qual nos sentimos atraídos como que por misteriosa afinidade eletiva, a nossa imaginação é como essa boa Scherazada das lendas maravilhosas: espalha por ele todo um resplendor de estranhas claridades.

Oliveira Vianna, Joaquim Nabuco'

A ruralidade, tida como um poderoso conformador da psicologia do homem brasileiro e de sua organização social foi uma das temáticas centrais da obra sociológica e política do jurista fluminense Francisco José de Oliveira Vianna. A experiência da vida no campo constituiu-se também como a temática central de uma das principais correntes da produção cultural brasileira na primeira metade do século XX, o regionalismo. Este artigo busca investigar a convergência entre o discurso regionalista, voltado para a representação literária do interior brasileiro em face do processo de modernização produtiva, e o sentido da ruralidade na história do país segundo a obra sociológica de Oliveira Vianna. Partimos do pressuposto de que a literatura rural e a sociologia de Vianna partilhavam de uma fundamentação programática similar, qual seja, a produção de um conhecimento renovado sobre a realidade do país no que esta possuiria de mais autêntico e profundo, enfatizando a diversidade de suas manifestações regionais. Tratava-se de

1 VIANNA, F. J. Oliveira. Joaquim Nabuco. In: Pequenos estudos de Psychologia social. São Paulo: Monteiro Lobato, 1921, p.193-194. 
redirecionar as atenções da intelectualidade para a busca da idiossincrasia nacional, que se esconderia nos espaços interiores, incontaminados pela modernidade homogeneizadora. Ao mesmo tempo em que a sociologia buscava definir, além da organização e da dinâmica social, as mentalidades, os comportamentos e os valores vigentes, a literatura enfatizava sua dimensão documental e analítica, buscando descrever e explicar o Brasil. Dadas estas correspondências, torna-se possível identificar, através de uma leitura abrangente e dialógica destes dois conjuntos de textos, a recorrência de determinadas percepções e simbolismos ligados ao campo no contexto de um processo de construção da identidade brasileira que ganha fôlego a partir das últimas décadas do século XIX. Em questão está, sobretudo, o imaginário da ruralidade e as concepções acerca de seu impacto sobre a psicologia do homem brasileiro. Dentro dos limites deste estudo, optamos por tomar como referência as obras de Oliveira Vianna publicadas até 1930, em especial o clássico Populações meridionais do Brasil e seus textos de caráter mais ensaístico que propriamente científico, e por concentrar nossa análise do discurso literário na obra de dois autores mineiros que, a nosso ver, afinam-se particularmente com alguns aspectos culturais da reflexão de Vianna: Godofredo Rangel e Afonso Arinos. Não pretendemos advogar possíveis influências recíprocas, mas consideramos que as obras destes autores compartilham interesses similares, ao se voltarem ao campo e ao passado como vias de acesso a uma verdade brasileira a ser desvelada e textualizada. ${ }^{2}$

Em seu discurso de posse no Instituto Histórico e Geográfico Brasileiro, em 1924, o próprio Oliveira Vianna explicitou a dimensão literária da história, em sua condição de "grande ciência" e, simultaneamente, de "grande arte", ou, como instrumento da "Verdade" e da "Beleza". ${ }^{3}$ Segundo ele, a ciência produzida em seu tempo oferecia poderosos instrumentos de apoio à produção de um saber histórico mais objetivo, o que o conduzia a inverter a lógica trivial de que o conhecimento do passado daria acesso à compreensão do contemporâneo: "é-nos possível esclarecer muita obscuridade da nossa História, suprir muita lacuna dos nossos arquivos, corrigir muita conjetura temerária dos nossos historiadores, com a observação atenta da realidade

2 Quando Afonso Arinos (1868-1916) faleceu, Oliveira Vianna (1883-1951) não havia ainda lançado seu primeiro livro, o que só viria a acontecer em 1920. Vianna foi contemporâneo de Godofredo Rangel (1884-1951), mas o principal romance deste último, Vida ociosa, foi concluído em 1915. É importante, todavia, considerar que a influência de Arinos sobreviveu a ele e mesmo intensificou-se após sua morte, tendo sido ele alçado à condição de "herói intelectual" dos movimentos nativistas a partir dos últimos anos da década de 1910. SEVCENKO, Nicolau. Orfeu extático na metrópole. São Paulo, sociedade e cultura nos frementes anos 20. São Paulo: Companhia das Letras, 1992, p.242. Sobre a recepção da obra de Vianna, ver VENANCIO, Giselle Martins. Na trama do arquivo: a trajetória de Oliveira Vianna (1883-1951). Rio de Janeiro: UFRJ, 2003 (História, Tese de doutorado). Disponível em: http://dominiopublico.qprocura.com.br/dp/16453/Na-trama-do-arquivo:-a-trajetoria-de-Oliveira-Vianna-1883 1951. html. Acesso em: 17/05/2010.

3 VIANNA, Oliveira. O valor pragmático do passado. In: O idealismo da constituição. $2^{a}$ ed. aumentada. São Paulo: Companhia Editora Nacional, 1939, p.331. 
presente". ${ }^{4}$ Mesmo ressaltando o papel das ciências naturais e humanas para a revelação da verdade, Vianna afirmava que o saber histórico nunca poderia dissociar-se do componente conjetural inerente, afinal, a qualquer forma de conhecimento científico. Uma história menos subjetiva, apoiada na cientificidade, não significaria, tampouco, uma história desprovida dos atrativos da eloquência, em especial porque o uso que Vianna faz do saber histórico é, sobretudo, instrumental, ou, em sua expressão, pragmático. Segundo ele, a história "pela natureza justamente do seu objetivo, justamente por ser uma ciência de evocação, versando matéria, a que falta o encanto das cousas vivas, não pode dispensar o auxílio das artes da ficção". ${ }^{5}$

Desta forma, o "encanto" e a "poesia" seriam necessários para que a história transcendesse o círculo estritamente científico e cumprisse sua função pragmática de despertar entre os cidadãos o sentimento de orgulho pelo passado nacional, o entusiasmo pelos grandes homens e pelos atos heroicos, a admiração pela criação de riqueza e de cultura que proporcionou a formação de um país e sua afirmação como comunidade autônoma e civilizada. Ou seja, o cumprimento da função cívica do saber histórico dependeria de seu poder de seduzir um amplo espectro de leitores, estimulando-os ao culto da ancestralidade. Portanto, não poderia haver patriotismo sem o amor à história induzido pelo apelo emocional da narrativa e dos instrumentos ficcionais que a tornavam capaz de engajar o leitor na devoção ao passado como um tempo de fundação, implantando o sentido da continuidade entre as gerações.

Caberia, ainda, à historiografia, a função de subsidiar a produção de conhecimento sobre o presente, indicando os elementos determinantes da formação nacional e, por consequência, suas possibilidades futuras, dentro de uma perspectiva realista proporcionada pela compreensão da psique coletiva, que definiria os limites e os potenciais de um dado grupo social. Retornando à origem seria possível observar as circunstâncias materiais e espirituais da gestação do espírito nacional, condição para a compreensão do presente e para uma intervenção eficiente na sociedade. O cultivo do passado não conduziria, assim, a um retorno, mas à busca de uma força propulsora. Nesta perspectiva, os atributos literários do texto histórico não eram vistos como um acessório, mas como uma das dimensões essenciais de sua necessária eficácia discursiva e de sua legitimação social.

Podemos compreender a relação da obra de Oliveira Vianna com a literatura em dois sentidos. O primeiro deles é a incorporação, pelo autor, de artifícios literários que estendem às suas análises político-sociológicas o cumprimento de uma "função pragmática" similar à que atribuía à história. Vianna adicionou a seus estudos o componente de eloquência fundamental

4 VIANNA, Oliveira. O valor pragmático do passado, p.326.

5 VIANNA, Oliveira. O valor pragmático do passado, p.332. 
para a realização de sua função de engajamento. Decerto, a compreensão estritamente científica de sua obra deixa de lado uma das dimensões fundamentais de seu discurso, a dimensão retórica. Aos instrumentos da linguagem e da tradição literária cabia a composição de um repertório imagético e mítico que se mostrava elemento não apenas de conhecimento, mas também de convencimento e adesão emocional, e, consequentemente, de mobilização em torno de ideais políticos. Valorizando a psicologia social e o estudo da cultura e das mentalidades, o autor fez um uso recorrente das "artes da ficção".

Em Populações Meridionais do Brasil, é frequente o uso de analogias históricas, imagens vigorosas e metáforas de forte apelo crítico, como a dos "fumadores de ópio", utilizada para definir o alheamento dos políticos brasileiros em relação à realidade nacional, fascinados pela visão fantasiosa de um Brasil examinado pelas lentes distorcidas de teorias baseadas na observação de outros povos. ${ }^{6} \mathrm{Na}$ introdução aos Pequenos estudos de psicologia social, toma de empréstimo a Kipling a fábula dos macacos que viviam numa cidade em ruínas e desprezavam os animais da selva, preferindo imitar atabalhoadamente os humanos e alimentar a ilusão de sua própria grandeza - pequena estória moralizante que lança sobre a elite brasileira a demolidora censura: "e temos assim com a bicharia do apólogo kiplingliano estes pontos comuns: a inconsciência, a volubilidade e o ridículo". 7 Em Problemas de política objetiva, apela à dramaticidade da narrativa de guerra do visconde de Taunay, A retirada da Laguna, para simbolizar os efeitos deletérios do desconhecimento da realidade nacional e a inutilidade de pretender intervir sobre ela em tais condições, defendendo a participação na vida pública de cidadãos capazes de fornecer ao Estado os saberes sorvidos da experiência direta na vida brasileira. ${ }^{8}$ Em Joaquim Nabuco, percorre sua própria memória para compor um testemunho rico de impressões visuais e sugestões cênicas, fotografando imaginariamente o homenageado, como "o modelo ideal da sua própria estátua". ${ }^{9}$

Um segundo sentido da interação da obra de Oliveira Vianna com a linguagem literária tem raízes na incorporação a seus estudos sociológicos de "lugares-comuns" que se infiltravam no pensamento social e na literatura como recursos consagrados de definição da identidade brasileira. Participando de uma mesma atmosfera intelectual, voltada para a reflexão sobre a mentalidade e as origens históricas do país, esses discursos difundiam determinadas noções que circulavam, de forma genérica, nas interpretações de sua cultura. Compreendemos o termo "lugar-comum" no sentido

6 VIANNA, Oliveira. Populações meridionais do Brasil. História - Organização - Psicologia. Populações rurais do Centro-sul. Paulistas - fluminenses - mineiros. $5^{a}$ ed. Rio de Janeiro: José Olympio, 1952, v.1, p.21. (1ªed. 1920).

7 VIANNA, F. J. Oliveira. Pequenos estudos de psicologia social, p.III.

8 VIANNA, Oliveira. Problemas de política objectiva. São Paulo: Companhia Editora Nacional, 1930

9 VIANNA, F. J. Oliveira. Joaquim Nabuco, p.206. 
adotado por Stella Bresciani em seu estudo sobre Oliveira Vianna, a partir de Myriam R. D'Allones: como um repertório de ampla circulação, composto de concepções, prejulgamentos, crenças, que possibilitam o intercâmbio de ideias e representações disseminadas em uma dada sociedade. ${ }^{10}$ É desta forma que buscamos, neste trabalho, estudar a confluência do pensamento de Vianna com a literatura. ${ }^{11}$

Lugares-comuns atuam, portanto, como pressupostos da reflexão intelectual, insinuando-se, com maior ou menor intensidade, tanto no discurso literário quanto nas Ciências Sociais. Oliveira Vianna não ficou imune a eles, mesmo que tenha desejado ser reconhecido como cientista, um estudioso capaz de compreender a sociedade brasileira a partir do arsenal teórico criado pelo saber científico, fazendo uso, sobretudo, do conhecimento sociológico de sua época, mas também da história, da etnografia, da filosofia, da demografia e dos estudos culturais. Por meio destas ferramentas lógicas, acreditava-se capaz de produzir um saber autóctone, objetivo e realista, encontrando soluções políticas adequadas à especificidade da condição brasileira e coerentes com a identidade nacional. Enfocaremos, a seguir, alguns dos "lugares-comuns" da vida intelectual brasileira na República Velha, a partir de Oliveira Vianna, Godofredo Rangel e Afonso Arinos: a essência rural do ser brasileiro; a identidade regional mineira; os valores morais da tradição rural; a superioridade racial da elite e a percepção da decadência do espírito nacional a partir da interpretação do passado histórico.

\section{De como ser uma saudade}

Já na primeira obra de Oliveira Vianna, Populações meridionais do Brasil, publicada em 1920, o sentido de ruralidade é imediatamente remetido à gênese das linhas distintivas da sociedade brasileira, pois resultante das necessidades práticas de adaptação do colonizador às extensas latitudes e às especificidades do meio geográfico brasileiro. O tipo nacional, em sua conformação psicológica e moral, diferenciar-se-ia do português que lhe deu origem à medida que, internado nas amplas solidões dos latifúndios coloniais, teria desenvolvido uma mentalidade própria, caracteristicamente rural:

Daí o traço fundamental da nossa psicologia nacional. Isto é, pelos costumes, pelas maneiras, em suma, pela feição mais íntima do seu caráter, o brasileiro é sempre, sempre se revela, sempre se afirma um homem do campo, à maneira

10 BRESCIANI, Maria Stella Martins. O charme da ciência e a sedução da objetividade. Oliveira Vianna entre intérpretes do Brasil. São Paulo: Editora Unesp, 2005, p.41.

11 Outro exemplo de tais possibilidades de leitura é esboçado por Kathrin Rosenfield, que define a literatura de João Guimarães Rosa como uma retomada do imaginário do clã parental descrito por Oliveira Vianna. ROSENFIELD, Kathrin Hozermayr. Desenveredando Rosa. A obra de J. G. Rosa e outros ensaios roseanos. Rio de Janeiro: Topbooks, 2006, p.17-21. 
antiga. O instinto urbano não está na sua índole; nem as maneiras e os hábitos urbanos. $^{12}$

Na obra de Vianna, o discurso histórico é chamado a identificar uma origem simbólica em relação à qual se estabelece uma oscilação constante entre aproximação e afastamento: a origem desdobra-se através do tempo, mas ela foge do alcance à medida que, mesmo que nunca ausente, também não pode ser acessada de forma imediata, uma vez que ela abriga as relações complexas estabelecidas pelas coisas em sua própria historicidade. ${ }^{13}$ A continuidade entre passado e presente na temporalidade da memória social e histórica é um tema fundamental para que Oliveira Vianna estabeleça o espaço simbólico da experiência rural na vida brasileira, conjugando de forma ambígua a percepção da ruptura e a necessária comunicação com a ancestralidade, dentro de um projeto político que tem por meta a intervenção sobre o contemporâneo e que, portanto, recorre ao discurso do passado mirando a missão objetiva de sensibilização do público em torno de valores nacionais assimilados a esta origem e dignificados por sua comunicação com ela.

Assim, a vida no campo é vista como uma experiência fundadora que exerceria ainda uma ação "silenciosa, obscura, subterrânea" sobre a mentalidade do brasileiro. ${ }^{14}$ Nas primeiras décadas do século XX, um dos lugares-comuns mais difundidos no Brasil era o de sua "vocação agrária", correlata a esta ruralidade essencial. Considerava-se que o país ocuparia, necessariamente, na divisão internacional do trabalho, o papel de exportador de gêneros agrícolas, em função da pretensa predestinação representada pela disponibilidade de terras agricultáveis e pelas condições geográficas favoráveis. A dita vocação criava um ambiente intelectual em que os destinos do país eram confundidos com os destinos da agricultura, sendo os valores do mundo rural preponderantes mesmo entre segmentos sociais modernos, que passavam a defender a atualização tecnológica do setor. ${ }^{15} \mathrm{O}$ mundo rural era, assim, visto como o universo de referência válido para se pensar o Brasil, uma vez que a cidade e a indústria eram definidas como fontes de descaracterização, de cosmopolitização e de ruptura com a tradição nacional. Ainda que os sentimentos em relação ao campo fossem diversos, era lá, indubitavelmente, que a verdade sobre o país deveria ser buscada.

$\mathrm{Na}$ visão de Oliveira Vianna, o campo modelou a alma nacional, imprimindo a ela seus traços peculiares. Em sua expressão: "O meio rural é, em toda a parte, um admirável conformador de almas. Dá-lhes a têmpera

12 VIANNA, Oliveira. Populações meridionais do Brasil, p.47. (grifo do autor)

13 FOUCAULT, Michel. As palavras e as coisas. Uma arqueologia das ciências humanas. $8^{\mathrm{a} e d .}$ São Paulo: Martins Fontes, 1999, p.453-463

14 VIANNA, Oliveira. Populações meridionais do Brasil, p.18.

15 MENDONÇA, Sonia Regina de. O ruralismo brasileiro (1888-1931). São Paulo: Hucitec, 1997. 
das grandes virtudes e as modela nas formas mais puras da moralidade". ${ }^{16}$ Segundo ele, desde que, no início da colonização, a aristocracia portuguesa internou-se pelos sertões, passou a sofrer um progressivo ensimesmamento, despojando-se de seus hábitos urbanos e adotando valores rústicos. O culto da honra, a valorização da vida familiar e doméstica, o exercício absoluto da autoridade patriarcal, o comportamento cavalheiresco e a índole comedida, a lealdade em torno da figura autoritária do chefe são alguns dos valores predominantes entre as classes aristocráticas, mantidos ao longo dos séculos e capazes de definir os traços fundamentais da mentalidade brasileira.

Na visão de Vianna, as altas classes rurais possuiriam também uma característica estabilidade, garantida por sua fixação à terra e pela transmissão dos valores patriarcais ao longo das gerações, de forma que também as relações sociais adquirem um caráter de permanência. As virtudes morais, os padrões de comportamento, os modos de vida e de sociabilidade desta aristocracia rural ter-se-iam mantido na longa duração graças a uma conduta social que valorizava a pureza do sangue ariano. Esta teria afiançado a manutenção das virtudes superiores das classes altas rurais, garantindo seu status social e a transmissão hereditária da "alma peninsular", modificada pelas condições do meio brasileiro.

O conto Manuel Lúcio, de Afonso Arinos, tem no personagem-título a simbolização das virtudes da ruralidade em seu nascedouro, sendo ele um descendente de bandeirantes, "tendo ainda nas veias o cálido sangue de sertanista". ${ }^{17}$ Ele é dotado de todos os traços distintivos do comportamento da elite agrária, similares aos identificados por Oliveira Vianna: austeridade, orgulho das origens, fidelidade ao código de honra, introversão. Transmitidas a ele por "herança, temperamento e educação", eram, portanto, virtudes étnicas e culturais de origem aristocrática, que o conduziam, segundo Arinos, a manter sua obediência ao pai, ou seja, à mentalidade patriarcal, pois o pai já estava morto há anos. ${ }^{18}$

Nos seus vinte e três anos, a alma se lhe desabotoara generosa e austera, aferrada aos antigos princípios de honra cavalheiresca, de melindre delicadíssimo. Insultado, por dez que fosse, julgava-se obrigado a tomar desforra ali mesmo. Professava um respeito religioso por tudo quanto Ihe vinha dos ascendentes usos e palavras, fatos e ações. Os amigos de seu pai eram os seus próprios, e julgava-os um prolongamento da pessoa querida que já levara a morte. (...) Altivo, orgulhoso, mas tímido nos modos, não sofria seu orgulho que alguém o achasse ridículo, a ele, Manuel: eis porque era taciturno, pouco amaneirado e cheio dessa original timidez, onde por força havia desconfiança. ${ }^{19}$

16 VIANNA, Oliveira. Populações meridionais do Brasil, p.65.

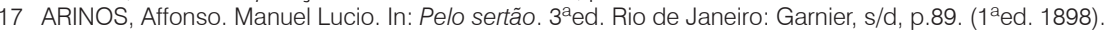

18 ARINOS, Affonso. Manuel Lucio, p.91.

19 ARINOS, Affonso. Manuel Lucio, p.89-90. 
A essas qualidades do espírito, o jovem filho da tradicional família Paes, instalado na região das Minas, aliava o corpo avigorado pela influência benfazeja do meio físico do sertão e pela liberdade das terras despovoadas, o que faz dele um português modificado, valorizado tanto pelas suas virtudes lusas quanto por sua aclimatação brasileira. É, também, um homem rural, não apenas administrando a fazenda em que vivia, como executando o trabalho nos campos - o que, segundo Arinos, não implicava em desonra. O personagem é também a encarnação do preceito civilizador num universo social ainda ameaçado pelas rebeliões de negros e indígenas, que, em sua fome de ouro, levantam-se contra a ordem estabelecida. Entretanto, quando se apaixona pela filha do guarda-mor que o adotara quando ainda criança, Manuel passa a se torturar por sua incapacidade de expressar seus sentimentos, debatendo-se entre "o orgulho, o amor, a altivez, a dedicação aos princípios". ${ }^{20}$ Artefato literário eclético, mescla de sensibilidade romântica, bravura de sertanista, nobreza cavalheiresca, espírito atormentado e orguIho desmedido, Manuel Lúcio é antes um arquétipo que um personagem, dado que o enredo do conto é secundário em relação à tipificação física e psicológica deste "mineiro ancestral", desconfiado, obstinado e tímido, mas dotado do orgulho da origem, da lealdade aos princípios, da devoção à tradição, da força civilizadora e do comportamento nobre que Oliveira Vianna identifica com as elites rurais do Centro-sul. Por outro lado, o conto regionalista típico de Arinos é $A$ esteireira, narrativa contemporânea da barbárie sertaneja em que uma mulata assassina a rival e chupa seu sangue para evitar ser descoberta. ${ }^{21}$

Não obstante, na visão de Oliveira Vianna, esta caracterização da identidade social brasileira, mesmo que exclusivamente entre as elites, somente é válida para a interpretação da história até 1888. Em sua visão, a Abolição da Escravatura representou a perda irrecuperável do espírito de integridade e permanência característico das classes altas da região das matas, momento de inflexão na história nacional que o autor pinta com tintas trágicas:

Daí em diante, depois da abolição do trabalho servil em 88, o nosso povo entra numa fase de desorganização profunda e geral, sem paralelo em toda a sua história. Todas as diretrizes da nossa evolução coletiva se acham, desde esta data, completamente quebradas e desviadas. ${ }^{22}$

O Brasil escravocrata dos tempos do Império é o paraíso perdido de Oliveira Vianna. Em várias de suas obras o escritor repisa o tema, enuncia-

20 ARINOS, Affonso. Manuel Lucio, p.93.

21 ARINOS, Affonso. A esteireira. In: Pelo sertão, p.65-82. A barbárie retratada neste conto causou espécie, e levou Arinos a publicar um artigo em defesa de sua representação realista do que seria a animalidade latente no homem dos sertões mineiros. ARINOS, Afonso. A nacionalização da arte: parecer de um curioso. In: Obra completa. Rio de Janeiro: INL, 1969, p.874-881.

22 VIANNA, Oliveira. Populações meridionais do Brasil, p.18. 
do na Introdução de Populações meridionais do Brasil. Mesmo antes desta publicação, em um de seus primeiros artigos, datado de 1918, Vianna define a Abolição como a quebra da linha evolutiva da civilização brasileira, que até então teria demonstrado constância e continuidade, sendo então perdidas as diretrizes do progresso histórico, assimilado à consolidação da mentalidade patriarcal e rural. Além disto, com o fim da escravidão, os fundamentos econômicos das comunidades rurais brasileiras teriam sido inteiramente arruinados. ${ }^{23}$ Em Evolução do povo brasileiro, seu livro de 1923, Vianna afirma que a decadência econômica das regiões tradicionais conduziu a aristocracia rural a um rebaixamento que a colocou em uma posição similar aos mais vulgares proletários do campo, ou que os conduziu à urbanização e a seu consequente desvirtuamento. A dissolução da velha ordem senhorial das fazendas do Centro-sul brasileiro - induzida pelo desmantelamento de sua base econômica e pelo desordenamento da estrutura social construída com alicerce na escravidão, somados à consequente queda da monarquia, que exercia uma ação centrípeta em torno da figura do Imperador - é o grande marco da história brasileira, na obra de Oliveira Vianna. A partir deste ponto de inflexão, define-se a ruptura com a ruralidade que caracterizaria o autêntico espírito brasileiro, à medida do enfraquecimento das elites tradicionais e de sua urbanização, em busca de colocação em cargos públicos.

A novela Vida ociosa, de Godofredo Rangel, reflete esta espécie de nostalgia rural, como narrativa de um retorno ao campo que acende a memória e o afeto pelo passado, movida pela consciência da descontinuidade e da perda. O texto explora temas privilegiados da obra de Oliveira Vianna: a decadência dos proprietários tradicionais em face das transformações econômicas e sociais no período pós-Abolição, a mentalidade das elites rurais do Centro-sul e a permanência do campo como espaço referencial de construção da identidade brasileira, no contexto de profundas mudanças sociais. No texto, a primeira imagem da fazenda do Córrego Fundo é a casa em ruínas em que vivem os velhos Próspero e Siá Marciana, outrora ricos fazendeiros, mas naquele momento extremamente pauperizados pela máfé e pelo comportamento argentário daqueles que um dia haviam contado com sua solidariedade. Próspero, personagem simbólico do patriarca das antigas fazendas mineiras, é um sobrevivente dos afortunados tempos da escravidão, que ele rememora com saudade, mas sem amargura:

Contou-me um dia que, no tempo de seu pai vivo, havia tantos escravos na fazenda, que davam de comer à molecada num cocho de que ainda no eirado restam vestígios. Despejavam ali dentro tachadas de canjiquinha e com uma buzina convocavam a miuçalha esparsa. De todas as senzalas, da casa, da

23 VIANNA, F. J. Oliveira. As pequenas comunidades mineiras. Revista do Brasil, São Paulo, n.31, p.219-233, 1918. 
horta, do pasto, negrinhos acudiam correndo, como uma horda de capetinhas nus. E as mãos avançavam sofregamente para a comida. 'Ficava estivado de negrinho, tudo pelado'. ${ }^{24}$

Metáfora de um paraíso perdido de inocência, simplicidade e abundância, esta imagem da época da escravidão sintoniza o tempo da memória com o tempo histórico, relegando o presente aos signos da decadência material e moral. Próspero, Siá Marciana e seu filho Américo, portadores das nobres virtudes da hospitalidade, da honra, da generosidade, do cultivo do espírito e da sobriedade, resistem à ação corruptora do tempo, e são observados como resquícios retrógrados de um passado incoerente com o presente materialista. Este descompasso é acentuado pelo próprio contraste entre a mentalidade tradicional daqueles que restaram no campo e a consciência inquieta do narrador Félix, um jovem juiz originário daquele universo ruralprovinciano, mas que chega à fazenda desadaptado ao compasso lento do tempo sertanejo, lutando contra o vazio e contra as sugestões de sua mente inquieta, ainda sincronizada com as atribulações da vida urbana. Sua visita, a princípio tediosa, converte-se aos poucos num reconfortante retorno à infância, que desperta sentimentos consagrados pelo imaginário pastoral: "Entrava-me uma sensação de paz, de lar e de bucolismo". 25 A representação da vida rural no romance de Rangel não difere do que lemos na obra de Oliveira Vianna, em sua exaltação da tranquilidade, da amenidade e da simplicidade das fazendas, gerando sentimentos que, a seu ver, implantaram-se definitivamente na psicologia do povo brasileiro. ${ }^{26}$

\section{Minas: o velho Brasil}

Dois textos publicados por Oliveira Vianna na Revista do Brasil, em 1918 e 1920, condensam sua percepção da ruralidade como elemento de identidade coletiva: As pequenas comunidades mineiras e Minas do lume e do pão. Ambos são um elogio de Minas Gerais, crônicas poético-sociológicas que buscam fazer convergir passado e presente, teoria e experiência, observação científica e literatura. Retirado por motivos de saúde nas regiões montanhosas de Minas, Oliveira Vianna imagina-se viajando não só no espaço, como também no tempo, vislumbrando uma via de acesso ao Brasil da tradição patriarcal e rural, à qual se sobrepunha um Brasil moderno em processo de urbanização. Em Minas, Vianna diz ver sancionadas pela observação direta determinadas noções a que já haveria chegado por meio

24 RANGEL, Godofredo. Vida ociosa. $2^{\mathrm{a} e d .}$ São Paulo: Companhia Editora Nacional, s/d, p.49. (1 ${ }^{\mathrm{a} e d .}$ 1920)

25 RANGEL, Godofredo. Vida ociosa, p.132.

26 VIANNA, Oliveira. Populações meridionais do Brasil, p.44. 
de inferências genéricas e da intuição apoiada no conhecimento das linhas evolutivas da civilização brasileira.

A paisagem da serra da Mantiqueira avistada do trem é uma primeira metáfora da mentalidade mineira: ao contrário da dramaticidade da Serra do Mar, surgem a seus olhos suaves colinas onduladas que jamais despertam sobressaltos, e sim uma melancólica e repousante sensação de amenidade, o que conduz o autor a evocar a imagem organicista da natureza como molde do espírito humano e fator de diferenciação dos povos:27 "É como ele, brando, pacífico, singelo, de um temperamento fino e sensível, todo feito de delicadeza e reserva. Esta reserva, porém, não lhe vem do orgulho, que nestas paragens é exotismo; mas, da timidez, que é grande e característica". ${ }^{28}$ Vimos acima como o protomineiro de Afonso Arinos, Manuel Lúcio, incorpora este lugar-comum da identidade regional.

A primeira observação propriamente sociológica do autor em Minas Gerais tem como objeto grandes grupos de trabalhadores rurais pobres, cerca de quinhentos homens, conduzidos pelo chefe local à inscrição eleitoral na cidade vizinha, e observados criteriosamente em busca da definição do aspecto e da mentalidade do homem do campo. Sua observação do tipo físico é desalentadora: homens de aparência alquebrada e doentia, cujas desarmônicas feições denunciavam a miscigenação do português com elementos "inferiores". Não obstante, o que Vianna enfatiza nesta observação é o que seria o avançado processo de arianização em curso, uma vez que sua argumentação tende a minimizar a presença dos tipos mulatos comuns e defender a acentuada presença do branco de alta estatura ou de tipos mestiços que tendem ao branco. Este argumento raciológico abre o caminho à caracterização do comportamento do grupo, que, segundo ele, portara-se todo o tempo com discrição, respeito e ordem. "Neste ponto, eram bem os representantes desse povo de serranos, honrados em cujo caráter há um tamanho lastro de equanimidade e doçura". ${ }^{29} \mathrm{~A}$ constatação de sua completa incultura política e de seus traços físicos desfavoráveis não dissipa esta imagem lisonjeira do povo do campo em Minas, calcada em valores éticos e em normas de comportamento implantados ao longo do tempo pela autoridade dos donos de terras.

No ambiente das pequenas cidades mineiras, Vianna anota o acelerado ritmo de modernização e atualização cultural, mas constata tratar-se de um progresso limitado às exterioridades, que não teria afetado a moralidade mineira:

Esta sociedade permanece estacionária no culto salutar das suas velhas tradições domésticas, dos seus velhos costumes familiares, no culto dos seus

27 THIESSE, Anne-Marie. La création des identités nationales. Europe XVIIle-XXe siècle. Paris: Seuil, 1999, p.159-160.

28 VIANNA, F. J. Oliveira. As pequenas comunidades mineiras, p.221.

29 VIANNA, F. J. Oliveira. As pequenas comunidades mineiras, p.223. 
preconceitos morais, nos seus zelos, nos seus escrúpulos, nas suas reservas de moralidade, pundonor e hombridade. Os personagens, principalmente os femininos dos romances de Alencar, de Taunay e de Bernardo Guimarães, nós os encontramos a cada passo por aqui, tangíveis e vivos, com toda a sua admirável psicologia de há meio século. Os seus escrúpulos, os seus zelos, os seus preconceitos morais e sociais aqui se conservam intactos, como nos grandes dias do Império, quando por estas paragens reinava o grave patriarcalismo das fazendas. ${ }^{30}$

Este repositório da mentalidade patriarcal imaginado por Vianna não por acaso desperta a memória de três precursores do regionalismo literário. No meio rural-provinciano a que se voltou esta literatura seria possível recuperar a ligação com o passado, mantido pelo isolamento dos espaços interiores, alheios à azáfama modernizadora do centro. Certamente, o espaço do regional define-se, sobretudo, pelo anacronismo, o que fez com que a narrativa histórica e a narrativa rural constantemente se confundissem na práxis literária regionalista. Mesmo que os modos de vida e os meios de vida tenham sido transformados - os primeiros mais do que os segundos, dado o desequilíbrio entre o gosto pelas coisas modernas e as condições efetivas de sua obtenção -, o que define a Minas de Oliveira Vianna é, neste momento, um romântico sentimentalismo, ainda que o autor não se furte a analisar as contradições e impasses enfrentados por estas comunidades em sua contemporaneidade.

Posteriormente, Vianna publicaria um segundo artigo sobre o tema, Minas do lume e do pão, tomando como ponto de partida a validade da proposta de se buscar uma identidade regional mineira, apesar das variações locais, - a construção de qualquer identidade social depende, em primeiro lugar, de instituir o próprio universo de referência, delimitando sua área de alcance e definindo manifestações "parciais" a serem reduzidas ao todo. Ou seja, o primeiro postulado de Vianna é justamente a existência de uma comunidade de sentido capaz de definir tanto o mineiro de Barbacena quanto o de Juiz de Fora e o de Belo Horizonte. A primeira referência da perquirição de Vianna sobre a identidade de Minas é uma reminiscência de sua infância no interior do Rio de Janeiro, uma canção de sentido obscuro que desperta nele, "como toda a impressão que se cunha na cera mole do nosso caráter em formação", a curiosidade por desvendar a psique mineira, embora o autor reconheça a existência de variantes locais e possíveis contaminações do tipo pela influência de outras regiões. ${ }^{31}$

A crônica de Vianna abre mão da análise da vida econômica, política e social do Estado para concentrar-se num único aspecto: a domesticidade, que define a vida em família e a hospitalidade oferecida aos adventícios. A

30 VIANNA, F. J. Oliveira. As pequenas comunidades mineiras, p.226-227.

31 VIANNA, F. J. Oliveira. Minas do lume e do pão. Revista do Brasil. São Paulo, n.56, p.289-306, 1920. 
primeira representação do caráter mineiro vem por analogia com a descrição dos bretões por Ernest Renan: um povo recolhido, desconfiado da vida exterior, orgulhoso, mais sentimental que ativo, que limita suas expansões ao ambiente familiar, devotado à família e ao lar. Segundo Viana: "Em Minas, o lar é um centro solar; todas as forças sociais cedem diante dessa atração poderosa e dominadora: a profunda concentração do homem em torno da ara doméstica como que cria ali o vácuo para fora de tudo o que não seja a família". ${ }^{32}$ Esta lógica é coerente com as tendências ideológicas conservadoras de crítica ao liberalismo que repercutiam no Brasil e argumentavam pela superioridade da família sobre o indivíduo, das formas comunitárias de vida em relação à institucionalidade moderna. ${ }^{33}$

Esta dedicação ao ambiente afetivo do lar marcaria profundamente o temperamento mineiro, induzindo-o à suavidade, à cordialidade, à delicadeza do trato, sobretudo nos contatos com os forasteiros. Para o anfitrião, não se tratava de pretextar familiaridade, de estabelecer relações de amizade imediatas ou de explicitar os sentimentos. A hospitalidade mineira representava não apenas a garantia de todo o conforto e bem-estar disponíveis, mas também a certeza de que sua "fina sensibilidade moral" saberia compreender o caráter dos visitantes, impedindo qualquer desavença ou desagrado. ${ }^{34}$ Em sua característica sociabilidade, o comportamento reservado do mineiro em face do visitante denotaria uma desconfiança que, uma vez superada, corria o risco de tornar-se uma exagerada confiança. Este comportamento seria, na visão de Vianna, tão característico das elites quanto dos homens do povo, sendo tão generalizadas as qualidades mineiras que mesmo suas multidões seriam ordenadas, pacatas, morigeradas.

A lealdade a este código de conduta é um dos temas fundamentais das inquietações do escritor Godofredo Rangel, que demonstra a consciência de uma identidade a ser nutrida e resguardada: "Sou mineiro da gema. É mais fácil o trem perder-me do que eu perder o trem" escreve ele, demonstrando a operacionalidade de um dos clichês da identidade regional mineira, mais brasileira que a dos demais brasileiros, segundo Oliveira Vianna. ${ }^{35} \mathrm{~A}$ condição de mineiro implicaria não apenas na auto-identificação do indivíduo, como na responsabilidade de fazer jus à tradição. Para Rangel, na voz de um de seus personagens, a fama da virtude mineira por excelência, a hospitalidade, é decerto merecida, mas a obrigação de desempenhar o papel cria deveres que ele considera demasiado penosos, o que o leva a definir-se como um "mineiro degenerado", por não ver sentido em abrigar viajantes desconhecidos. Era previsível, portanto, seu desagrado ao rece-

32 VIANNA, F. J. Oliveira. Minas do lume e do pão, p.293.

33 BRESCIANI, Maria Stella Martins. O charme da ciência e a sedução da objetividade, p.40.

34 VIANNA, F. J. Oliveira. Minas do lume e do pão, p.292.

35 RANGEL, Godofredo. Os oitenta contos. In: Andorinhas. São Paulo: Monteiro Lobato, 1922, p.26. 
ber um misterioso telegrama vindo de Soledade comunicando a chegada, naquele mesmo dia, de uns tais "Azeredos" que ele não se lembrava quem pudesse ser. Apesar disto, a preocupação em atender a família visitante passa a obcecá-lo: fosse quem fosse, era necessário preparar-se para recebê-los. "Não era que desejasse então quebrar as velhas tradições mineiras de hospitalidade", mas a tarefa era-lhe custosa, e acabou por demandar-lhe um esforço considerável. ${ }^{36}$ Mobilizando toda a vizinhança e desorganizando completamente sua casa diminuta, muito diversa das grandes moradas fazendeiras, prepara-se para cumprir sua obrigação e parte à estação para buscar os hóspedes, que ele sequer conhecia, mas sobre os quais já tinha recolhido informações:

De caminho procurava coordenar minha confusão interior, recapitulando o que ficara resolvido: no escritório dormiria a velha; no meu quarto, o genro professor e consorte; na sala de visitas, as duas solteironas; eu... - Muito boa! Esquecerame de mim próprio. Mas era o menos; contanto que nada faltasse aos demais! À custa de algum ligeiro torcicolo passaria a noite na cadeira de lona. ${ }^{37}$

Ao final, quem estava de chegada eram sua mulher e seu filho, sendo os tais "Azeredos" frutos de um mero erro do telegrafista. O conto de Rangel encena a adesão involuntária, mas percebida como obrigatória, aos preceitos de sociabilidade que, segundo Oliveira Vianna, teriam sido estabelecidos ao longo da longa vivência brasileira no isolamento das grandes fazendas, e especialmente conservados na cultura de Minas Gerais. Em cena está o que Vianna denominou "a Minas íntima e doméstica, a Minas que se reúne para compartir o pão da amizade, e junto ao lume larário para os ritos do culto da hospitalidade". ${ }^{38} \mathrm{Na}$ narrativa de Rangel, mesmo desgostoso, o "mineiro degenerado" segue à risca as regras da hospitalidade, e sua recusa racional ao cumprimento deste papel não exerce qualquer influência em face das motivações inconscientes de seu comportamento e, decerto, da obrigatoriedade de cumprir os deveres socialmente consagrados como marcas de distinção e dignidade.

A manutenção dos princípios da ruralidade patriarcal em Minas Gerais é atribuída por Oliveira Vianna às condições peculiares de sua colonização: ao contrário dos paulistas que, quando se expandiram pelo Brasil, haviam já sofrido um processo de aculturação em contato com o meio físico-geográfico brasileiro, as grandes massas de colonos portugueses que acorreram a Minas em busca do ouro não haveriam ainda sofrido qualquer modificação prévia, o que teria conferido a elas melhores condições de manutenção de sua cultura original. Portanto, até o momento em que começaram a sofrer

36 RANGEL, Godofredo. O telegramma. In: Andorinhas, p.54

37 RANGEL, Godofredo. O telegramma, p.61.

38 VIANNA, F. J. Oliveira. Minas do lume e do pão, p.291. 
a influência do novo meio físico-social, os portugueses que formaram a base da ocupação do território mineiro mantiveram íntegras e concentradas as particularidades de seu povo, que assim se teriam transmitido de forma mais pura ao espírito mineiro que aos demais povos do Centro-sul. Ou seja, a peculiaridade de Minas Gerais residiria em sua "lusitanidade" superior, o que tornaria possível identificar naquele estado propensões e modos de vida muito similares aos dos colonizadores do norte de Portugal. Nacional e regional confundem-se no texto de Oliveira Vianna, à medida que a idiossincrasia mineira acaba por ser traduzida como a quintessência da alma brasileira, um hiato na temporalidade histórica que permitiria o acesso direto ao passado dentro do presente.

De Minas guardo também o encanto de me ter revelado um Brasil, de que eu tinha uma lembrança muito vaga, porque lembrança da minha mais verde juvenilidade: Brasil patriarcal, de que falavam os meus avós, conservando ainda, quase intactos, esses nossos costumes, tão cheios de penetrante poesia, que a civilização dos litorais, na sua expansão incoercível, vai rapidamente destruindo. ${ }^{39}$

\section{O fardo do homem urbano}

No entanto, este elogio da vida patriarcal não exclui o progresso, uma vez que, segundo Oliveira Vianna, era necessário conservar as tradições "dentro das formas evolutivas da civilização". ${ }^{40}$ Ao enviar a tradição aos domínios mais profundos da mentalidade brasileira, o autor a compatibiliza com a ideia de transformação da sociedade. São exemplos disto seu elogio da manutenção das virtudes rurais no meio urbano, conciliados com os modos modernos de vida, e sua análise das possibilidades de desenvolvimento econômico das localidades interioranas mantenedoras do sentido profundo da tradição, no sentido de compatibilizar os desejos e sensibilidades modernas com suas condições efetivas de progresso social, seja pela agricultura, seja pela indústria (o sociólogo inclina-se, neste momento, pela primeira). ${ }^{41}$ Virtudes brasileiras por excelência, estas teriam tido, em Minas, condições de se conservar, mesmo em condições sócio-culturais totalmente diversas de seu ambiente de origem, como no caso da nova capital:

Mas a alma mineira, feita do bom metal antigo, o metal da nossa antiga simplicidade patriarcal, entra nessa cidade e, ao invés de se deixar absorver por essas maravilhas, derrama, ao contrário, sobre elas, sobre esses esplendores

39 VIANNA, F. J. Oliveira. Minas do lume e do pão, p.300.

40 VIANNA, F. J. Oliveira. Minas do lume e do pão, p.300.

41 Na visão de José Murilo de Carvalho, a partir de 1932, com sua nomeação para o Ministério do Trabalho, Oliveira Vianna abandonou seu sonho passadista de retorno ao ruralismo patriarcal, convencendo-se de que modernidade era, efetivamente, o tempo da indústria e da cidade. CARVALHO, José Murilo de. A utopia de Oliveira Vianna. Estudos Históricos, Rio de Janeiro, v.4, n.7, 1991. 
de arquitetura, sobre essas avenidas, sobre essas praças, tão radiosamente batidas do sol, a sua tranqüilidade, a sua frugalidade, o seu isolamento, o seu doce espírito familiar, que trouxe das suas vivendas rurais, onde só habitam a modéstia, o sossego e a paz! ${ }^{42}$

Coerentemente com esta lógica de elogio à ruralidade como refúgio da tradição, é possível a Vianna encontrar a mentalidade tradicional formada no recesso das grandes fazendas patriarcais mesmo em meio ao cinematógrafo, aos campos de patinação e ao telefone. Segundo ele, uma das principais consequências do isolamento das famílias fazendeiras nos latifúndios é a restrição da sociabilidade, imposta pelas grandes distâncias e pela não-criação de laços estáveis de solidariedade social, uma vez que, na solidão de seus grandes domínios, os proprietários voltavam-se unicamente à família e ao clã de agregados, dispensando, em função da inexistência de inimigos comuns, de pressões do poder ou de luta de classes, a cooperação em prol de demandas coletivas. Isto explicaria também uma radical limitação da vida social. Enclausurado no ambiente doméstico, mesmo o mineiro da grande cidade evitaria os espaços públicos de sociabilidade e a vida ao ar livre.

A obra de Oliveira Vianna marca, simultaneamente, o elogio da continuidade e a consciência da ruptura com a tradição, o que podemos observar também em Vida ociosa, de Rangel. No romance, o jovem urbanizado de origem rural, posicionado no emprego público - destino convencional dos filhos da antiga elite agrária, diz Oliveira Vianna - distancia-se do passado também porque passa a guiar-se por valores distintos daqueles mantidos pelo código de honra das famílias patriarcais do meio rural brasileiro. No episódio final do romance, Félix recebe a inédita visita de seus amigos fazendeiros, que "viviam tão consigo e ilhados na sua pobreza, amavam tanto seus hábitos tranqüilos", que sua presença no meio urbano desperta estranheza. Sua missão na cidade é anunciada em tom solene pelo velho Próspero, vestido em sua sobrecasaca de gala: vinha para acertar as contas com o jovem amigo, que, sempre que se hospedava na fazenda, deixava uma determinada quantia em dinheiro, a título de ressarcimento pelas despesas que sua visita representava aos anfitriões. A "vingança dos seus piraquaras" consistia em oferecer ao jovem juiz uma valiosa jóia, um anel de grau adquirido com o dinheiro que haviam recebido dele ao longo dos anos. "Se não aceitar como devolução, receberá como um brinde de amigos", conclui o velho. ${ }^{43} \mathrm{~A}$ condição de penúria material em que viviam não afeta o cumprimento do dever de hospitalidade da família, que vê seu orgulho ofendido pela compensação financeira. Ou, nas palavras de Oliveira Vian-

42 VIANNA, F. J. Oliveira. Minas do lume e do pão, p.298

43 RANGEL, Godofredo. Vida ociosa, p.248. 
na, "hoje ainda é proverbial a correção e o escrúpulo dos nossos matutos em questão de dinheiro. Mesmo os pobres e deserdados não desmentem a bela tradição de inteireza rural". ${ }^{44}$ Por sua vez, a contrapartida oferecida pelo amigo juiz obedece às formas então vigentes de favorecimento: Félix serve-se de sua influência para criar uma escola rural na localidade em que viviam os velhos, nomeando professor o amigo Américo.

Simultaneamente a esta percepção da mudança cultural, Godofredo Rangel adotou como tema o significado da herança rural para o homem urbano, ou seja, a manutenção dos valores da ruralidade nos meios modernos. O conto Meu parente é uma ilustração quase caricata do instinto familista identificado por Oliveira Vianna como outra das características da tradição patriarcal brasileira integralmente conservada em Minas Gerais. O narrador é (novamente) Félix, um jovem magistrado que já de início manifesta sua frustração por ter que viver distante da família e seu contentamento sempre que surgia um parente, mesmo remoto, a quem podia oferecer sua hospitalidade e seus favores, encontrando uma oportunidade de desfilar sua árvore genealógica, em busca dessa "comunhão espiritual que cimenta amizades duradouras entre pessoas do mesmo sangue". ${ }^{45} \mathrm{O}$ comportamento do personagem repete a caracterização da sociedade bretã por Renan, citada por Vianna como idêntica ao do mineiro: "Em nenhuma outra o laço de sangue tem sido mais forte, criou mais deveres, ligou o homem ao seu semelhante com tanta extensão e tão profundamente". ${ }^{46}$ Os laços de sangue, prossegue Oliveira Vianna em sua leitura, implicam em obrigações e criam profunda comunhão, de modo que seriam tão fortes que dois parentes desconhecidos poderiam ser capazes de reconhecer-se em qualquer lugar. Ainda que, na visão de Vianna, todos os brasileiros fossem homens profundamente ligados ao lar e à família, este elemento do caráter brasileiro teria em Minas "os contornos mais sutis e íntimos". ${ }^{47}$

Certa feita, o Félix de Godofredo Rangel encontra casualmente na rua, saindo de um pobre casebre, um homem comum, de aparência desagradável, vestido como operário, cujo nome raro coincidia com o de um seu primo distante e desconhecido, Oriental. Aproximando-se do estranho, constata, pelo nome de sua mãe (Sá Maria) e sua origem (para os lados de Virgínia), tratar-se de seu parente. A profissão de pedreiro, os hábitos nômades, a mão calejada despertam a repulsa do juiz, que conclui, entretanto, que um parente decaído era, pelo contrário, merecedor de sua compaixão e incentivo. Entusiasmado com a descoberta, Félix oferece-lhe o melhor quarto de sua casa e destina a ele todos os privilégios de sua hospitalidade. Infe-

44 VIANNA, Oliveira. Populações meridionais do Brasil, p.70.

45 RANGEL, Godofredo. Meu parente. In: Andorinhas, p.78.

46 RENAN, Cf. VIANNA, F. J. Oliveira. Minas do lume e do pão, p.291.

47 VIANNA, F. J. Oliveira. Minas do lume e do pão, p.291. 
lizmente, sua expectativa de encontrar um interlocutor para suas histórias de família são frustradas pela "memória detestável" do primo, que não se lembrava de nenhum dos parentes do juiz, mas se recordava de "criaturas estranhas": "O Nhano, a Chica do Quirino, o Quirino da Chica, o Anardino do Anastácio, nomes de gentinha, estava-se vendo". ${ }^{48}$

Apesar de lamentar a "péssima sociedade" em que o parente se criara, e de sentir-se envergonhado ao passear com ele pela rua, a "voz do sangue" fala mais alto: "Co'os diabos! Fosse o que fosse era meu primo, carne de minha carne, a quem eu devia levantar de sua condição humílima". ${ }^{49}$ Félix não apenas introduz o parente aos amigos, como se dispõe a corrigir seus modos rudes, transformando-o num homem "perfeitamente civilizado". Dentro da melhor tradição patriarcal, a obrigação de acolhê-lo passa a implicar também no exercício da autoridade e de uma pedagogia moralizadora. O primo, no entanto, preferia a companhia dos bêbados, jogadores de carteado e valentões, e "dançava em batuques da negrada". ${ }^{50}$ Os vícios da bebida e do furto - interpretado por Félix como cleptomania - não demovem o jovem juiz de proteger o parente e livrá-lo constantemente da polícia, mesmo que com o prejuízo de sua própria reputação. Enfim, ele acaba por descobrir que aquele não era seu primo - uma obviedade que apenas seu fascínio pelos laços de sangue podia obscurecer: "E desse dia em diante senti-me imensamente aliviado, vendo-me livre dele, da morrinha dele, do Nhano, do Quirino da Chica e do resto da caterva e até hoje não sei o que foi feito do meu 'parente' Oriental". ${ }^{51}$

O conto de Rangel é particularmente curioso, não apenas pelo absurdo da situação criada pelo exacerbado instinto de família do protagonista, como pelo desenvolvimento do enredo, que parte da relação familiar capaz de criar uma comunhão imediata e indissolúvel entre dois homens que jamais haviam se visto antes, em direção à radical alteridade de dois homens que parecem não fazer parte de uma mesma sociedade. A condição familiar conferia ao "primo" a imunidade de um parente de juiz, mesmo que seu comportamento fosse socialmente nocivo, mas a família se impõe à sociedade. Na linguagem de Oliveira Vianna, podemos dizer que o conto traduz a mentalidade gerada pela exacerbação da solidariedade parental (e de clã) no ambiente das grandes fazendas do Centro-sul, em contraste com a inexistência de vínculos estáveis de cooperação e solidariedade social entre as classes. No caso da fábula familista de Rangel, enquanto protege o "primo", o juiz mantém e acaba por estimular seu comportamento antissocial, que passa a se beneficiar da impunidade garantida.

48 RANGEL, Godofredo. Meu parente, p.85.

49 RANGEL, Godofredo. Meu parente, p.86.

50 RANGEL, Godofredo. Meu parente, p.88.

51 RANGEL, Godofredo. Meu parente, p.96. 
Não há nenhuma referência explícita à condição racial do "primo" no conto em questão, ainda que a imagem da inferioridade física seja coerente com as "feições um tanto repulsivas" que o descrevem, e com sua interação com as ditas "raças inferiores". ${ }^{52} \mathrm{O}$ falso primo é visto como um homem inferior, física e moralmente, e os dois aspectos são indissociáveis, pois se acentua que o verdadeiro parente era avesso à bebida, ao fumo, ao jogo e ao crime. Some-se a isto a insistência de Félix em defender as prerrogativas do sangue, que apontam para o orgulho da origem racial - daí seu fascínio por sua genealogia. Há, ainda, uma diferenciação clara entre a cultura das classes baixas (a "caterva") e a cultura de elite, que tem na repulsa de Félix em relação aos nomes da família do "primo" uma óbvia manifestação.

Em Populações meridionais do Brasil, a representação do proletariado dos campos é, o mais das vezes, pouco generosa, em contraste com a nobilitação da tradicional mentalidade dos latifundiários. A posição social da elite adquire, assim, uma fundamentação naturalista, baseada na equivalência entre etnicidade e moral. Segundo Oliveira Vianna, ao contrário da estabilidade das relações familiares na elite, onde o poder absoluto do patriarca imporia a obediência aos códigos de conduta tradicionais, nas camadas inferiores as ligações efêmeras e instáveis inibiriam a afirmação da autoridade patriarcal - no conto de Godofredo Rangel, é observada a constrangedora desinibição do "primo" ao relatar "segredos de família", no caso o comportamento condenável de sua esposa, "uma bisca", da qual vivia "largado" ${ }^{33} \mathrm{Na}$ visão de Vianna, as classes aristocráticas teriam uma moral exclusivista, enquanto, entre os pobres a integridade de caráter teria sido progressivamente corrompida pela miscigenação entre tipos brancos de origem plebeia, negros e indígenas. Isto teria consequências negativas sobre sua moralidade, tendendo à dissolução do controle familiar e social.

Oliveira Vianna supõe, portanto, a existência de um continuum condição racial - posição social - moralidade - apego às tradições, associando a pureza de costumes à pureza de sangue, de maneira que a plebe rural é caracterizada como "o lugar social dos elementos inferiores da nacionalidade, daqueles em que predominam na cor, no caráter, na inteligência, os sangues abastardados". ${ }^{4}$ Da mesma forma, a caracterização dos personagens do conto Meu parente, de Godofredo Rangel, opõe o perfeitamente civilizado descendente das elites agrárias a um representante do "baixo povo", com todas as suas características de depravação moral - crime, vício, violência. O lugar social de onde fala Rangel é, portanto, análogo àquele assumido por Oliveira Vianna, ambos porta-vozes tardios da tradicional mentalidade rural brasileira, ambos conscientes de sua superação, ainda que atados ao seu universo de valores.

52 RANGEL, Godofredo. Meu parente, p.78

53 RANGEL, Godofredo. Meu parente, p.80-81.

54 VIANNA, Oliveira. Populações meridionais do Brasil, p.160. 


\title{
A história como destino
}

A relação entre povo e elite é um dos aspectos mais problemáticos da análise de Oliveira Vianna, pois a detração das classes inferiores perturba a construção cultural de uma identidade coletiva: a hierarquização racialsocial do país implanta um incômodo princípio de alteridade no interior do que deveria ser a construção de um sentido amplo e genérico de comunidade social, a nação. Já em outros momentos de sua obra, no entanto, as qualidades da classe latifundiária são expandidas de modo a conformar uma identidade social fundada na ruralidade, independentemente da classe social, mesmo reafirmada a superioridade da elite:

\begin{abstract}
Quatro qualidades possui o nosso homem rural, cuja influência na nossa história política é imensa; quatro qualidades que constituem o mais genuíno florão da nossa nobreza territorial. Uma é a fidelidade à palavra dada. Outra a probidade. Outra a respeitabilidade. Outra, a independência moral.

Essas qualidades, pelo menos as duas primeiras, existem mais ou menos difusas por toda a massa da população rural; mas, onde se fazem preexcelentes e fulgem com brilho inconfundível é na nobreza fazendeira. ${ }^{55}$
\end{abstract}

Em textos mais evocativos e menos sistemáticos da obra de Oliveira Vianna encontramos com maior frequência tais imagens positivas da plebe rural. Em 1924, por exemplo, ele publicou na Revista do Brasil uma carta a Mário Sette, em agradecimento à dedicatória de seu livro O vigia da casa grande. A celebração da continuidade histórica como traço distintivo do comportamento das elites tradicionais legitima-as através da imagem da profundidade e do enraizamento, oposta ao caráter instável e aos instintos nômades enfatizados na descrição do comportamento da plebe rural tanto por Vianna em seu Populações meridionais do Brasil quanto por Sette no romance $O$ vigia da casa grande. ${ }^{56}$ No entanto, nesta carta, Vianna elogiava a capacidade do autor de compreender a psicologia do homem pobre do campo e de captar o que seria o "fundo moral" comum à aristocracia dos latifúndios e aos homens do povo, feitos "da mesma nobreza, do mesmo cavalheirismo inconsciente, dos mesmos sentimentos de fidelidade, honra, justiça, bondade!"57

Ainda que reconhecendo no romance também a representação do traço instintivo e selvagem destas populações, a imagem do homem rural difundida na curta resenha de Vianna é a de um "lidador medieval", idealização romântica não de todo coerente com o realismo da narrativa, e menos ainda com a caracterização das deficiências morais da plebe rural em Populações meridionais do Brasil. Em outro trecho da carta, Vianna observa a frequente

55 VIANNA, Oliveira. Populações meridionais do Brasil, p.70.

56 SETTE, Mario. O vigia da casa grande. Porto: Chardron, 1924.

57 VIANNA, F. J. Oliveira. O vigia da casa grande. Revista do Brasil, São Paulo, n.107, 1924 
ingratidão dos proprietários em face da dedicação dos trabalhadores, "esta humilde gente que moureja e vegeta na obscuridade dos nossos sertões". 58 Em sua visão, sua obra e a de Mário Sette teriam em comum a compaixão pelo homem pobre do campo, o que, em seu caso, Vianna define como resultado de uma transmissão intergeracional dos sentimentos de identificação com os modos de vida e a índole dos caboclos rurais. ${ }^{59}$

O sociólogo identifica neste momento, portanto, uma alma coletiva que definiria tanto a classe proprietária quanto o povo, e que poderíamos compreender como o cerne da identidade nacional, assimilada pelo sociólogo fluminense à marca dignificante da ruralidade. A contradição entre a visão positiva do proletariado rural enunciada por este texto sobre o romance de Mário Sette e a condenação do caráter instável, da moralidade falha, dos instintos primitivos, da tendência à miscigenação e do desapego à terra afirmados na obra sociológica de Oliveira Vianna é patente. ${ }^{60}$ Não por acaso, na terceira edição dos Pequenos estudos de Psicologia social, em texto que estende ao homem do povo as virtudes da aristocracia rural, Vianna redige uma nota declarando que o otimismo por ele manifestado no momento da primeira edição do livro era fruto de uma intenção explícita de combater o negativismo que permanecia entre os políticos acerca do caráter pretensamente dissoluto do brasileiro. ${ }^{61}$ Observa-se, portanto, a convivência de dois níveis distintos de argumentação na obra de Vianna: uma observação sociológica pretensamente neutra e construída a partir de matrizes científicas, inclinada à desvalorização dos tipos mestiços da plebe rural, por um lado, e por outro lado o discurso doutrinador, preocupado com o impacto das ideias sobre a realidade e disposto a curvá-las ao cumprimento de uma função social.

A condição de descendente da tradicional elite latifundiária fluminense condiciona, na visão do próprio Oliveira Vianna, seus sentimentos a respeito dos trabalhadores pobres do campo. Tratava-se, segundo ele, de uma comiseração transmitida de forma "já hereditária, já subconsciente", ao longo de "quatro gerações de senhores de terra", o que confere à sua descrição das virtudes da ruralidade uma aura de autoelogio. ${ }^{62} \mathrm{~A}$ evocação passadista do patrimônio das elites latifundiárias é uma viagem sentimental

58 VIANNA, F. J. Oliveira. O vigia da casa grande, p.247

59 VIANNA, F. J. Oliveira. O vigia da casa grande, p.247.

60 Decerto, a narrativa de Sette não é apenas uma ficção documental em torno dos tipos populares, dos costumes e do cotidiano dos engenhos de cana de Pernambuco, mas também um texto de observação sociológica, polêmica política e crítica social, voltado para a interpretação da experiência histórica e o traçado de um projeto de mudança social em torno da modernização produtiva e da condenação do comportamento político das oligarquias tradicionais consumidas em suas disputas de poder. Muitas das discussões levantadas pelo romance foram, certamente, influenciadas pela obra sociológica de Oliveira Vianna, mas, nesta carta de agradecimento, o sociólogo passa ao largo de um debate mais aprofundado. SETTE, Mario. O vigia da casa grande.

61 VIANNA, Oliveira. Degeneração aparente do caráter nacional. In: Pequenos estudos de Psychologia social. $3^{\mathrm{a} e d .}$ São Paulo: Companhia Editora Nacional, 1942, p.22-24.

62 VIANNA, F. J. Oliveira. O vigia da casa-grande, p.247. 
que reporta o autor a uma ancestralidade idealizada, na qual se projetam seus próprios valores, em intercessão com o que seriam os valores brasileiros por excelência. Ainda que a imagem desta elite proprietária de terras transmitida pelo autor não seja todo o tempo positiva - pois teria conduzido a uma formação social em que os valores particularistas se impuseram aos valores coletivos de solidariedade social, necessários ao estabelecimento da ordem legal-institucional do Estado-nação, ao fim é a iniciativa política de representantes desta própria elite que salva a nacionalidade, moldandoa de forma a fazer frente aos poderes locais e possibilitar a fundação de uma estrutura estatal centralizada. As virtudes que Oliveira Vianna descreveu como características das elites rurais do Centro-sul do país são vistas não apenas como qualidades de caráter e comportamento, mas também como a fonte das virtudes públicas desejáveis que, segundo o autor, têm sua melhor encarnação nos políticos conservadores do Império, a "idade de ouro" da história política brasileira. ${ }^{63}$

Este pensamento articula-se ao próprio projeto modernizador de Oliveira Vianna, que busca legitimação na coerência entre a centralização estatal defendida por ele e as tendências mais profundas da alma nacional, assimiladas à tradição conservadora: a índole moderada, o temperamento equilibrado, os costumes austeros, o culto da honra e a estrita moralidade. A análise cultural, voltada para a descrição do comportamento, do gênio e da sensibilidade dos homens egressos das grandes fazendas do Centrosul, alia-se a uma análise política em que a manutenção da integridade territorial e a organização jurídica e institucional do país são vistas como resultantes da ação de atores políticos excepcionais capazes de impor ao restante do país o princípio da autoridade estatal, em detrimento dos interesses dos clãs regionais e do ideário liberal importado dos países avançados. O elogio da ação centralizadora e realista destes políticos legitima historicamente o projeto político de Vianna, que se insere nesta tradição do pensamento conservador brasileiro e dá continuidade a ela. Sendo ele próprio um descendente das elites tradicionais, seu discurso adquire um sentido autorreferencial, validando a si mesmo por sua vocação hereditária. ${ }^{64}$ Dada a relação entre origem racial/familiar e conduta social, este programa extrapola a argumentação racional, convertendo-se na retomada da herança simbólica dos patriarcas da nacionalidade. A partir daí, como observou José Murilo de Carvalho, é possível qualificar o próprio modelo de Estado

63 VIANNA, F. J. Oliveira. Joaquim Nabuco, p.193.

64 A demonstração mais inequívoca deste componente autorreferencial da obra de Oliveira Vianna é seu discurso de homenagem a Alberto de Oliveira, pronunciado em 20 de julho de 1940 em sua recepção na Academia Brasileira de Letras, no qual a caracterização das virtudes rurais personalizadas pelas tradicionais famílias fazendeiras do interior fluminense remete à origem social do poeta e às suas próprias. VIANNA, Oliveira. Discurso do Sr. Oliveira Vianna. Sessão solene do dia 20 de julho de 1940. In: Discursos acadêmicos. Rio de Janeiro: Academia Brasileira de Letras, t.III (1936-1950), 2007, p.535-575. 
defendido por Vianna como patriarcal, ${ }^{65}$ fundamentado em um princípio de concentração do poder aliado tanto à razão quanto à afetividade.

É imensa a ação educadora do pater-familias sobre os filhos, parentes e agregados, adscritos a seu poder. É o pater-familias que, por exemplo dá noivo às filhas, escolhendo-o segundo as conveniências da posição e da fortuna. Ele é quem consente no casamento do filho, embora já em maioridade. Ele é quem Ihe determina a profissão, ou the destina uma função na economia da fazenda. Ele é quem instala na sua vizinhança os domínios dos filhos casados, e nunca deixa de exercer sobre eles a sua absoluta ascendência patriarcal. Ele é quem os disciplina, quando menores, com um rigor que hoje parecerá bárbaro, tamanha a severidade e a rudeza. Por esse tempo, os filhos têm pelos pais um respeito que raia pelo terror (...). O sentimento de respeito aos mais velhos e de obediência à sua autoridade, tão generalizado outrora no nosso meio rural, é também uma resultante dessa organização cesarista da antiga família fazendeira. ${ }^{66}$

Portanto, o elogio da tradição patriarcalista pode ser compreendido como uma metáfora da autoridade do Estado nacional centralizado e sua personalização no líder (o pai), destinado a exercer um poder moralizante sobre a família (os cidadãos), transformando seu domínio exclusivista na força disciplinadora e organizadora da vida social, exercendo rigorosa tutela dos incapazes, e estabelecendo a ordem em seu imenso latifúndio (o país), através da condensação do poder em torno de uma única fonte de autoridade.

Afonso Arinos tampouco esconde a presunção de sua própria ascendência superior. Vários de seus contos têm como tema a busca de comunicação com o passado, através da documentação histórica e da evocação de suas relíquias materiais. Monarquista, Arinos observava o Brasil republicano como um país em degeneração, buscando na história referências para construir uma pedagogia nacionalista capaz de fornecer balizas para o julgamento do presente, como em um artigo de 1898 em que fazia um balanço do governo de Prudente de Morais:

Por desgraça nossa, estamos na contingência de louvar como obra de patriota nesta mal-aventurada República a simples defesa dos princípios cardeais de uma civilização incipiente; ou, n'outros termos, retrogradamos mais de meio século em nossa vida de povo independente, para recomeçarmos a arcar com as dificuldades que o pulso de Feijó, o gênio organizador de Vasconcellos e a persuasiva eloquência de Evaristo já tinham domado há sessenta anos. ${ }^{67}$

65 CARVALHO, José Murilo de. A utopia de Oliveira Vianna, p.93.

66 VIANNA, F. J. Oliveira. Minas do lume e do pão, p.433.

67 ARINOS, Affonso. Festas acabadas. In: Notas do dia. Commemorando. São Paulo: Andrade, Mello \& Comp. 1900, p.257. 
Em que pese este saudosismo imperial, que seria revivido por Oliveira Vianna, Arinos tinha predileção pelo Brasil colônia, espaço simbólico onde se movem personagens aos quais ele se sente ligado por laços de sangue. Os Mello Franco eram aparentados desde o século XVIII à família Caldeira Brant, que teve como mais célebre membro Felisberto Caldeira Brant, bandeirante e contratador de diamantes no Arraial do Tijuco, personagem principal de um conto e de uma peça de teatro escritos por Arinos. ${ }^{68} \mathrm{Ambos}$ os textos de ficção histórica alçam o contratador de diamantes à qualidade de rebelde e herói nacional, em luta contra o arbítrio exercido pela Coroa portuguesa. A personagem em destaque é sua sobrinha, a jovem paulista Cotinha, entusiasta da independência e guardiã do espírito de honra das mulheres de Piratininga. Ao lado do contratador, Cotinha encena, como observou Antônio Dimas, a faceta ideológica do congraçamento entre as aristocráticas famílias tradicionais de Minas Gerais e São Paulo. ${ }^{69}$

Em tempos de ascensão social e econômica dos imigrantes, a consagração da origem lusitana e a busca das fontes mais remotas do espírito nacional acendiam os ânimos nativistas da elite tradicional, o que o espírito de libertação contra o jugo português defendido pela peça de Arinos não obstava, ainda que uma cuidadosa operação retórica fosse exigida: a autonomização da colônia faria com que alguns dos filhos de Portugal pagassem pelos crimes da opressão e da ganância, mas outros filhos seriam salvos, pois, mesmo quando a Coroa perdesse seus domínios na América, a alma portuguesa haveria de se manter viva no Novo Mundo, através da raça e da língua, recriando no Brasil, seu primogênito, um novo Portugal..$^{70} \mathrm{O}$ discurso histórico, neste momento, converte-se em mero artifício, curvado sob o peso do anacronismo que deseja impor aos tempos coloniais os sentidos de identidade nacional, amor à pátria e defesa da unidade territorial. As algemas que prendem o contratador, diz ele, "simbolizam para mim agora a unidade perpétua e indissolúvel das capitanias!". ${ }^{71}$ Assim, o sonho de libertação e de manutenção da unidade nacional ganha um profeta que

68 Sobre a genealogia de Arinos, ver ATHAYDE, Tristão de. Affonso Arinos. Rio de Janeiro: Annuário do Brasil; Lisboa/ Porto: Seara Nova/Renascença Portuguesa, 1922, p.2-3. Felisberto Caldeira Brant é também citado por Arinos em seu romance histórico O mestre de campo, em trecho em que um alferes a serviço da Coroa acusa-o de "pretender levantar os povos destas Minas com o tenebroso e abominável intento de forrá-los à sujeição de el-Rey".ARINOS, Affonso. O mestre de campo. Romance do século dezoito. Rio de Janeiro: Francisco Alves, 1918, p.55.

69 DIMAS, Antônio. Bilac, o jornalista. Ensaios. São Paulo/Campinas: Imprensa Oficial do Estado de São Paulo/Edusp/ Editora da Universidade Estadual de Campinas, 2006, p.71. Casado com uma sobrinha do Conselheiro Antônio Prado, o prestígio de Arinos entre a alta sociedade paulista garantiu a célebre representação da peça, em maio de 1919, no Teatro Municipal de São Paulo, festiva congregação das famílias tradicionais do estado, em uma atmosfera de ascensão dos ânimos nacionalistas que autenticava o mergulho no passado colonial e na cultura popular brasileira como contrapartida à guerra europeia. As posteriores excursões modernistas de descoberta do Brasil, em particular as visitas às cidades coloniais mineiras, em 1924, ecoam este evento fundador. SEVCENKO, Nicolau. Orfeu extático na metrópole, p.240-247.

70 ARINOS, Afonso. O contratador dos diamantes. Peça brasileira. Rio de Janeiro: Serviço Nacional de Teatro, 1973 p.51. $\left(1^{\mathrm{a} e d .}\right.$ 1917)

71 ARINOS, Afonso. O contratador dos diamantes, p.56. 
nobilita sua descendência e projeta nela sua missão nacionalista, revestida de passadismo e sertanismo:

Céu, que tanta vez me serviste de tenda de bandeirante, quando, estirado num couro, lá no fundo dos sertões, pousava ao relento, com os olhos pregados nas tuas estrelas e o espírito perdido em sonhos de riquezas e de glória! Ó terra que me acalentaste menino, mãe generosa, que a mim, soldado da fortuna, me deste os seios onde se apojam as aluviões de ouro e onde se concentram os diamantes! Terra das minhas venturas e das minhas desditas! A ti - já que não receberás o meu derradeiro alento - te confio a sorte de minha mulher, o destino de meus filhos! Guarda-os, forma-lhes o coração com o mesmo amor que vitimou seu pai! ${ }^{72}$

Este autocongratulatório compêndio dramático-literário é ilustrativo da inquietação das elites tradicionais brasileiras nas primeiras décadas do século XX, em meio à diversificação da estrutura econômico-social e à emergência de projetos políticos alternativos que tornavam mais complexo o panorama da vida brasileira. Um passado tranquilizador possibilitava a recondução imaginária destas elites ao poder, em um espaço ideal em que a memória histórica ficcionalizada é convertida em predestinação, mirando a crítica e a ação sobre o presente. Não haveria, sugere Arinos em texto de 1903, descendentes de bandeirantes e inconfidentes entre os "vendilhões da honra nacional, bulrões da fazenda pública, escravos ignominiosos de tiranetes ridículos e das imposições estrangeiras". ${ }^{73}$ Ou seja, a República parecia ter colocado o Brasil em mãos erradas.

Ao buscar a intercessão do discurso histórico e sociológico de Oliveira Vianna com a produção literária de Godofredo Rangel e Afonso Arinos, observamos o quanto a análise destes autores alimentou-se de sentimentos, desejos e símbolos difusos, lugares-comuns de uma sociedade que se percebe em processo de transformação, mas que, nas primeiras décadas do século XX ainda tateia na definição de um projeto hegemônico de futuro. $\mathrm{O}$ discurso destes autores responde à mudança através da busca de um sentido da permanência nutrido por "verdades" endossadas por acordos coletivos subjacentes, que instituem a crença em uma identidade brasileira rural, patriarcal, familista, lusa e conservadora e a projetam no futuro, visivelmente abalada pelo sentimento da mudança histórica. Deste mergulho no passado, o presente volta um tanto aturdido: não mais somos o que éramos, mas o que éramos ainda permanece em nós. Ao subscrever estas mitologias identitárias, e se reconstruir continuamente a partir delas, a cultura brasileira oscila entre relíquias e profecias, que ligam o contemporâneo ao tempo de fundação e às utopias regeneradoras. A partir dos últimos anos

72 ARINOS, Afonso. O contratador dos diamantes, p.65-66.

73 ARINOS, Affonso. Atalaia bandeirante. In: Historias e paizagens. Rio de Janeiro: Francisco Alves, 1921, p.99. 
do século XIX, a literatura regionalista assume, neste panorama, um papel fundamental: ainda que sua aliança com o nacionalismo seja indissolúvel, sua narrativa é, muitas das vezes, o registro perturbador da barbárie renitente, da hibridez do real, do pretérito fantasmagórico. A revelação das alteridades radicais lidas como resíduos de uma era superada na escala da evolução social disputa espaço com as imagens oníricas que perpassam as narrativas mítico-históricas e as representações de uma ruralidade ideal. Ao reafirmar a presença do passado, as obras de fundo sertanejo e/ou histórico de Godofredo Rangel e Afonso Arinos reinstituem o sentimento de continuidade com uma origem que transmite mensagens ao futuro, e que, na obra de Oliveira Vianna, revela uma analogia com sua própria missão política. O desajuste entre o passadismo persistente e os valores modernos confere um tom paradoxal às obras destes autores, que sentem o chão ruir sob seus pés fincados no terreno aparentemente seguro da tradição, a ser doravante ressignificada. 